\title{
Article
}

\section{Understanding dementia in South Asian populations, an exploration of knowledge and awareness}

Poole, Chloe, Harrison, Joanna and Hill, James Edward

Available at http://clok.uclan.ac.uk/38309/

Poole, Chloe, Harrison, Joanna ORCID: 0000-0001-8963-7240 and Hill, James Edward ORCID: 0000-0003-1430-6927 (2021) Understanding dementia in South Asian populations, an exploration of knowledge and awareness. British Journal of Neuroscience Nursing, 17 (4). ISSN 1747-0307

It is advisable to refer to the publisher's version if you intend to cite from the work. 10.12968/bjnn.2021.17.4.156

For more information about UCLan's research in this area go to http://www.uclan.ac.uk/researchgroups/ and search for < name of research Group>.

For information about Research generally at UCLan please go to http://www.uclan.ac.uk/research/

All outputs in CLoK are protected by Intellectual Property Rights law, including Copyright law. Copyright, IPR and Moral Rights for the works on this site are retained by the individual authors and/or other copyright owners. Terms and conditions for use of this material are defined in the policies page.

\section{CLoK}

Central Lancashire online Knowledge www.clok.uclan.ac.uk

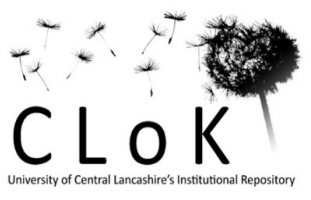




\section{Understanding dementia in South Asian populations, an exploration of knowledge and awareness}

Chloe Poole, Research Support Officer ${ }^{1}$

Joanna Harrison, Research Fellow ${ }^{2}$

James Hill, Senior Research Fellow ${ }^{2}$

${ }^{1}$ Research and Development, East Lancashire Hospitals NHS Trust

${ }^{2}$ Synthesis, Economic Evaluation and Decision Science (SEEDS), University of Central Lancashire

Corresponding author: Joanna Harrison, jharrison12@uclan.ac.uk

\section{Abstract}

Evidence for the lived experience of dementia within the South Asian community was limited to individual studies across different contexts. Knowledge was lacking into the attitudes and beliefs about dementia within this community. This article critically appraises and evaluates a qualitative synthesis of evidence that explores the knowledge and awareness of dementia in South Asians.

\section{Acknowledgement}

This report is independent research funded by the National Institute for Health Research Applied Research Collaboration North West Coast (ARC NWC). The views expressed in this publication are those of the author(s) and not necessarily those of the National Institute for Health Research, the NHS, or the Department of Health and Social Care. 
A commentary based on the following systematic review: Hossain M, Crossland J, Stores R, Dewey A, Hakak Y. Awareness and understanding of dementia in South Asians: a synthesis of qualitative evidence. Dementia. 2020;19(5):1441-1473. https://doi.org/10.1177/1471301218800641

Key points:

- There is a lack of knowledge about dementia among individuals with dementia and family caregivers within the South Asian population

- Family caregiving creates great challenges to the physical and mental health of carers with little to no support

- Delays to seeking a diagnosis of dementia and appropriate support are experienced as a consequence of limited knowledge and cultural beliefs.

Introduction

An estimated $6.5 \%$ of adults over 65 have dementia in the United Kingdom (Matthews et al, 2013). Evidence for the prevalence, experience and treatment of dementia in the UK South Asian population is limited (Blakemore et al, 2018). Given the higher prevalence of risk factors for dementia within this population, such as hypertension and diabetes (Singh et al, 2019), the number of those affected by dementia may also be above average. The lived experiences of people with dementia from the South Asian population are, therefore, of interest. Experiences of dementia diagnosis in the general population have been previously reported, including the negative impact of stigma, feeling vulnerable, loss of control and wanting to maintain personal agency (Xanthopoulou and McCabe, 2019). The experiences of informal caregivers for those with dementia have also been described and include both unpredictable expectations and the restrictive nature of providing care (Macdonald et al, 2020). However, little attention has been paid to the South Asian population's experience of dementia. The qualitative synthesis by Hossain et al (2020) aimed to address this through gaining an awareness and understanding of the attitudes, perceptions and beliefs of the South Asian community about dementia, identifying research gaps and producing new insights. 


\section{Aims of commentary}

This commentary aims to critically appraise the methods used in the systematic review by Hossain et al (2020) and expand upon the findings in the context of clinical practice.

\section{Methods}

Following an initial scoping search, an all-inclusive search was undertaken using multiple databases from 1970 to 2014 . The search was not limited to nationality or language. References were also searched from included studies, unpublished literature and relevant sources identified by hand searching. Only studies which reported views about knowledge, perceptions, experience or beliefs of South Asian people with a diagnosis of dementia or their families in community or primary care settings were included. If translation into the English language was not possible and additional information from the author was unavailable, studies were excluded. Title, abstract and full paper screening was undertaken by two reviewers independently, with arbitration by a third reviewer. Assessment of bias was undertaken using the Joanna Briggs Institute Qualitative Assessment and Review Instrument, now referred to as the JBI Critical Appraisal Checklist for Qualitative Research (Lockwood 2020) and studies were synthesised using a meta-aggregation approach (Pearson, 2004).

Results

The search results identified 2515 papers, of which 187 were examined fully and 17 assessed for methodological quality. Four further studies were excluded, due to insufficient reporting of the researchers' influence (their own beliefs/values) and a lack of participant validity (providing verbatim quotations). Some 13 studies were included in the qualitative synthesis.

Included studies were conducted predominantly in the UK, with two in India and one each in Canada and Pakistan, all between 2001-2013. All studies used interviews as their primary means for data collection, and analytical methods such as grounded theory. In total, there were 214 participants 
across the 13 studies, of which 145 were family carers, 53 service providers and 16 people with dementia. Most participants across the 13 studies were from Indian and Pakistani backgrounds.

The meta-synthesis produced three themes and seven categories (Table 1).

\section{Table 1: Meta-Synthesised Themes and corresponding categories}

\begin{tabular}{|l|l|}
\hline Theme & Category \\
\hline understanding of dementia & $\begin{array}{l}\text { 1. Lack of knowledge and cultural beliefs about dementia } \\
\text { Experience of family }\end{array}$ \\
caregiving & $\begin{array}{l}\text { 1. Obligations to family care } \\
\text { 2. The challenges of family care }\end{array}$ \\
\hline Attitudes towards & $\begin{array}{l}\text { 1. The pathway to a dementia diagnosis } \\
\text { dementia care provisions }\end{array}$ \\
\hline
\end{tabular}

Poor awareness and understanding of dementia was the most significant theme describedspecifically, a lack of knowledge about dementia among both individuals with dementia and the ir family carers. Early symptoms of dementia were perceived as unproblematic symptoms of the normal ageing process or linked to other psychosocial, physical, and mental health problems, such as social isolation, diabetes and depression. A visit to the GP or any trauma-related hospital admission appeared to be the first steps in recognising a diagnosis of dementia among family caregivers. Cultural beliefs also informed understanding in a small number of studies, with beliefs varying from dementia as a punishment to a medium in which one's relationship with Goddeepened. Several studies reported that cultural and religious factors influenced the level of stigma associated with dementia, subsequently interfering with the willingness and ability of those with dementia and their family to participate in the community. There was also a moral stigma attached to not being able to care for a relative with dementia at home, adding extra pressure to family caregivers. 
Most studies described the experience of family caregiving, a role which often fell to unmarried daughters or daughter-in-laws. A feeling of 'obligation' or religious duty was frequently reported among family members caring for their older relatives, who did not perceive care as a pleasant task. However, caring for family in this way was also perceived as an opportunity to provide reciprocal love and respect to older family members. Most of the studies reported that family caring created great challenges to the physical and mental health of carers, in addition to problems relating to finance, employment and practical daily living. A notable difficulty was managing personal hygiene, as this led to upset for the person with dementia and embarrassment for family members. Family carers often received little to no support; once an official diagnosis was made, they felt an expectation to put the needs of the relative above their own and found it difficult to express this burden to healthcare professionals. A quarter of the studies noted that prayer and continued faith in God were used by family carers as religious coping mechanisms.

The final theme explores attitudes towards dementia care provision. Nearly half of the studies reported on the process of reaching a diagnosis, with almost all carers reporting delays in seeking help due to lack of knowledge, confusion around early signs, fear, and stigma of diagnosis. Family carers would often seek help from friends and family first, and an official diagnosis was often a result of attending the GP for a different physical problem. Due to an acceptance of traditional family caregiver roles, there were also limited expectations for seeking and taking up external help and services. Difficulties were also experienced with available services, including: a lack of information in the appropriate language; frustrations with healthcare services (complicated GP services, hospitals without appropriate services); and experience of discrimination (from rigid service providers). Almost all of the families reported that their relative wished to stay at home; while a few wanted in-house respite care, they often did not take this service up, due to concerns over shame and privacy. Similarly, there were also concerns about the cultural appropriateness of care homes, including language barriers, access to South Asian food and provision of personal care needs by younger staff or of the 
opposite sex. Family members did not often look for more culturally appropriate settings, due to feeling ashamed to do so.

\section{Commentary}

Using the Joanna Briggs Critical Appraisal Tool for Systematic reviews, all the criteria were judged to be satisfactory for this review (Aromataris et al, 2015). However, the search strategy was undertaken 6 years earlier than publication, meaning more relevant studies could be missing. The process of data screening on title in the first instance may also have introduced some error, due to the possibility of excluding a misleading yet relevant title. The reviewer also acknowledges that, due to problems with sampling and recruitment, country of settlement studies failed to represent individual South Asian populations. Despite these inconsistencies, it was deemed that this systematic review provided an accurate and comprehensive summary of the available study results that addressed the question of interest.

Lack of knowledge and understanding of dementia appeared to underly all the themes identified in this review and ultimately shaped the course of care, from receiving a diagnosis to seeking help or support. A key point described in this process is the misidentification of dementia symptoms as a normal part of ageing, rather than the result of a degenerative disease. Lack of knowledge was further hindered by the stigma permeating cultural perceptions of dementia, which discouraged seeking support outside of the family caregiving role. This is significant for family caregivers' wellbeing, as receiving support and information has been recognised as key to improving their knowledge and ability to cope and manage their own needs (Bressan et al, 2020). Awareness of dementia services was not a key finding in this review, with the focus on accessibility issues and dissatisfaction with services. However, this has been identified in another study, where ethnic minority groups in the UK (British Indian, Afro-Caribbean, East and Central European) reported a lack of awareness in how to access social services support and specific dementia services (Parveen et al, 2017). 
In order to improve knowledge of dementia, including its cause, symptoms, diagnosis and treatment, it may be helpful to target education at both healthcare professionals and relevant members of the community. Interventions, such as communication skills training and internet-based support, have been found to have a positive impact on family caregivers of people with dementia, including the improvement of knowledge and mood (Eggenberger et al, 2013; Leng et al, 2020). However, such interventions have not been specifically explored in minority ethnic groups. To facilitate awareness within these communities, factors highlighted by the review should be included into interventions, such as the use of language-appropriate resources and a clear explanation of what the term dementia means, given the lack of an equivalent term in native South Asian languages. A lot of sensitivity would be needed in producing this information, and working with local communities, religious and community leaders could be beneficial. A clearer understanding for healthcare professionals of the cultural beliefs that impact on family caregiving - such as the reliance on female members of the family, difficulties in managing personal care or the stigma attached to seeking care outside of the home-may also help with healthcare interactions and cultural support.

Although most of the issues identified in this review are culturally specific, it is important to consider that some themes may be universal. In a study of barriers and facilitators to formal dementia care across eight European countries, similar themes were identified by people with dementia, informal caregivers and healthcare professionals. These included a lack of knowledge and information about dementia, feeling a 'duty to care', and worries over stigma and privacy (Stephan et al, 2018).

There are limitations associated with the research studies and participants included in this review. Over half of the studies were designed to explore dementia within the wider black and minority ethnic community and were not exclusive to the South Asian population. More research is needed within this population to explore the specific cultural and religious issues raised. Most of the participants in the review were family caregivers, meaning that individuals with dementia were under-represented. This is not limited to research in South Asian communities, as there appears to be a shortage of qualitative 
research in this area. Future research should strive to obtain the experiences of people with dementia, perhaps thinking of ways to collect data away from traditional interview techniques. Finally, the age of participants is not clear, which is significant for understanding any differences in generational knowledge of dementia. Therefore, it is difficult to make broad generalisations, particularly given the many other variables, such as language, education, employment, housing and social status. Further research should aim to provide as much detail as possible on participants to improve understanding of different groups.

\section{CPD reflective questions}

How do we best address the support needs of people with dementia and their family caregivers in South Asian populations?

How do we improve healthcare professionals' understanding of culturally sensitive associations with dementia?

Keywords: South Asian, dementia, family caregivers

\section{References}

Aromataris E, Fernandez R, Godfrey CM et al. Summarizing systematic reviews: methodological development, conduct and reporting of an umbrella review approach. International Journal of Evidence-Based Healthcare 2015;13(3):132-140. https//doi.org/10.1097/XEB.0000000000000055

Blakemore A, Kenning C, Mirza N, et al. Dementia in UK South Asians: a scoping review of the literature. BMJ Open. 2018;8:e020290. http://dx.doi.org/10.1136/bmjopen-2017-020290 Bressan V, Visintini C, Palese A. What do family caregivers of people with dementia need? A mixedmethod systematic review. Health Soc Care Community. 2020;28(6):1942-1960. https://doi.org/10.1111/hsc. 13048 
Eggenberger E, Heimerl K, Bennett MI. Communication skills training in dementia care: a systematic review of effectiveness, training content, and didactic methods in different care settings. Int Psychogeriatr. 2013;25(3):345-58. https://doi.org/10.1017/S1041610212001664

Hossain M, Crossland J, Stores R, Dewey A, Hakak Y. Awareness and understanding of dementia in South Asians: A synthesis of qualitative evidence. Dementia. 2020;19(5):1441-1473. https://doi.org/ $10.1177 / 1471301218800641$.

Leng M, Zhao Y, Xiao H, Li C, Wang Z. Internet-Based Supportive Interventions for Family Caregivers of People With Dementia: Systematic Review and Meta-Analysis. J Med Internet Res. 2020; 22(9):e19468. https://doi.org/doi: 10.2196/19468

Lockwood C, Porrit K, Munn Z, et al. Chapter 2: Systematic reviews of qualitative evidence. In: Aromataris E, Munn Z (Editors). JBI Manual for Evidence Synthesis. JBI, 2020. Available from https://synthesismanual.jbi.global. https://doi.org/10.46658/JBIMES-20-03

Macdonald M, Martin-Misener R, Weeks Let al. Experiences and perceptions of spousal/partner caregivers providing care for community-dwelling adults with dementia: a qualitative systematic review. JBI Evidence Synthesis. 2020;18(4):647-703. https://doi.org/10.11124/JBISRIR-2017003774

Matthews FE, Arthur A, Barnes LE et al. A two-decade comparison of prevalence of dementia in individuals aged 65 years and older from three geographical areas of England: results of the Cognitive Function and Ageing Study I and II. Lancet. 2013;382(9902):1405-12. https://doi.org/10.1016/S0140-6736(13)61570-6 
Parveen S, Peltier C, Oyebode, JR. Perceptions of dementia and use of services in minority ethnic communities: a scoping exercise. Health and Social Care in the Community. 2017;25(2):734-742. https://doi.org/10.1111/hsc.12363

Pearson, A. Balancing the evidence: incorporating the synthesis of qualitative data into systematic reviews. JBI Reports. 2004;2(2):45-64. https://doi.org/10.1111/j.1479-6988.2004.00008.x

Singh K, Patel SA, Biswas S, et al. Multimorbidity in South Asian adults: prevalence, risk factors and mortality. J Public Health (Oxf). 2019;41(1):80-89. https://doi.org/10.1093/pubmed/fdy017

Stephan A, Bieber A, Hopper L et al. Barriers and facilitators to the access to and use of formal dementia care: findings of a focus group study with people with dementia, informal carers and health and social care professionals in eight European countries. BMC Geriatr. 2018;18(131). https://doi.org/10.1186/s12877-018-0816-1.

Xanthopoulou P, McCabe R. Subjective experiences of cognitive decline and receiving a diagnosis of dementia: qualitative interviews with people recently diagnosed in memory clinics in the UK. BMJ Open. 2019;9(8):e026071. https://doi.org/10.1136/bmjopen-2018-026071 